\title{
Attitudes of agricultural extension' personnel towards electronic extension in Assiut governorate, Egypt
}

\author{
Abdelsalam M. F. S. ${ }^{{ }^{*}}$, Mahmoud A. M. Z. \\ ${ }^{a}$ Agricultural Extension and Rural Sociology Department, Faculty of Agriculture, Al-Azhar University, Assuit, Egypt \\ ${ }^{b}$ Extension and Training Department, Central Laboratory for Organic Agriculture, ARC, Giza, Egypt
}

\begin{abstract}
The main objectives of this paper were: determine attitudes of Personnel in agricultural extension centers (Respondents) towards utilization of Information communication technologies in extension work, determine personnel' attitudes towards applications of e- extension (computer, internet, and mobile phone), identify attitudes of the respondents towards the electronic extension service as a final product for the use of these applications, and then to identify the problems of Eextension in Assiut Governorate, and determine the correlation between the level of the respondents' orientation towards Eextension and its applications and the independent characteristics of the researchers (age, educational qualification, training in communication and information technology, supervision space, and experience in the field of agricultural extension). The respondents' attitudes toward E-extension were determined by using 57 directional phrases that were collected from previous measures used by the same purpose Verma et. al. (2014), and Kumar and Ratnakar (2011), and these phrases are classified into five main sections: phrases that measure trends toward the use of communication and information technology in extension work (22 phrases), phrases that measure attitudes toward computer use at extension work ( 9 phrases), expressions measuring trends toward the use of the Internet in indicative work (14 phrases), expressions measuring trends toward mobile phone use in extension work ( 6 phrases), and phrases measuring electronic service ( 6 phrases). To measure the attitudes of the respondents, a stepwise triple scale was constructed according to Likert method, and the grades were allocated as follows (3), neutral (2) and disagree (1). This, and the degrees obtained by each respondent were collected to express the level of attitudes towards E-extension and its applications, and the total degrees of the subjects were divided according to the actual extent of the degrees. Data were collected by means of personal interview using a questionnaire prepared for this purpose. Percentages, and frequency distribution used for data processing and analysis using SPSS program. The results of the field research indicated that the attitudes of the respondents towards E-extension were positive, especially with regard to the use of the mobile phone in the extension work, and that the level of direction was high in all its applications except for electronic service as a final product of the indicative process was average, and perhaps This is due to the novelty of this service.
\end{abstract}

Keywords: E-extension, ettitudes, Agricultural extension.

* Corresponding author: Abdelsalam M. F. S.,

E-mail address: mohamedabdelsalam.4919@azhar.edu.eg 


\title{
اتجاهات العاملين بالجهاز الإرشادى الزر اعى نحو الإرشاد الإلكترونى بمحافظة أسيوط بجمهورية مصر الإدي العربية الإنية
}

\author{
محمد فوزي سالمان عبدالسلام' ، أدهم محمد زكي محمود׳

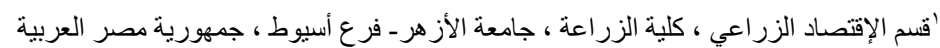

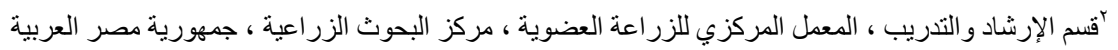

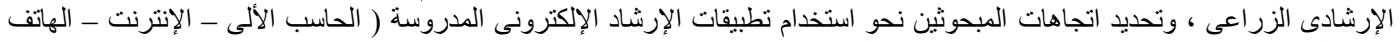

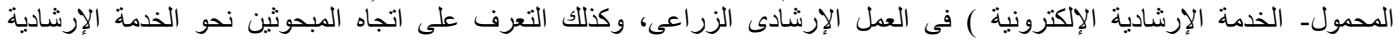

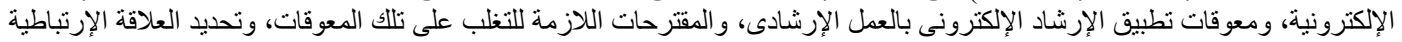

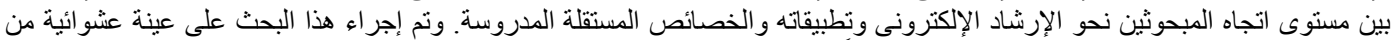

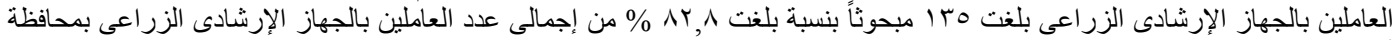

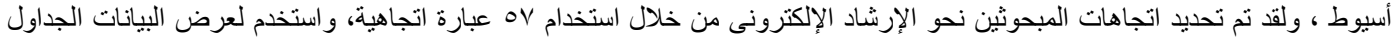

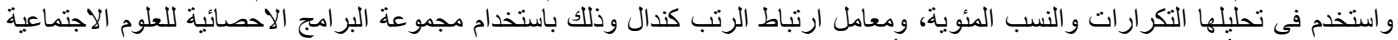

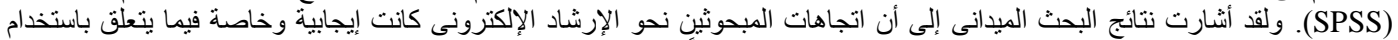

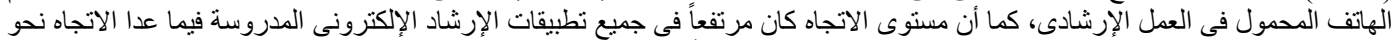
الخدمة الإرشادية الإكترونية كمنتج نهائى للعملية الإرشادية كان متوسطاً، وربما يرجع ذلك الكئك إلى حداثة الخدمة الإرشادية الإلكترونية.

كلمات دالة: الإرشاد الإلكترونى، الاتجاهات، تكنولوجيا المعلومات و الاتصال. 


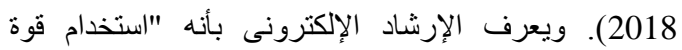

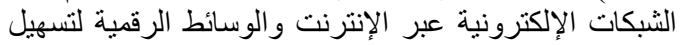

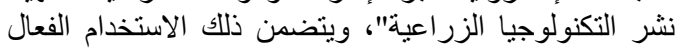

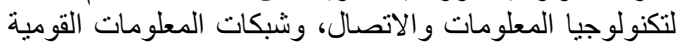

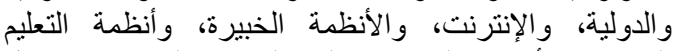

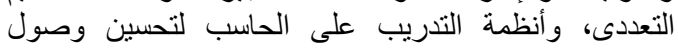

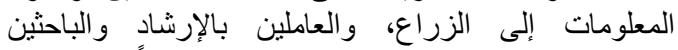

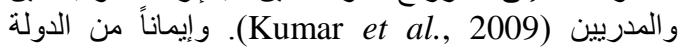

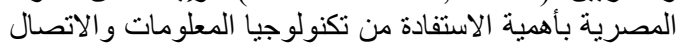

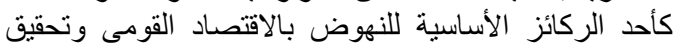

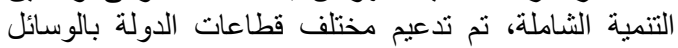

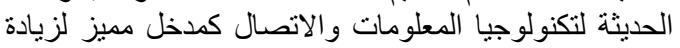

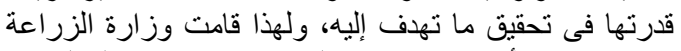

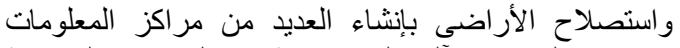

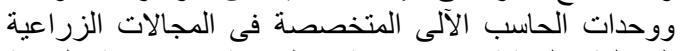

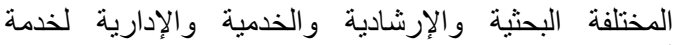

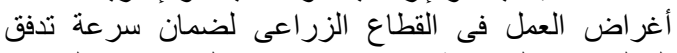

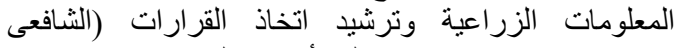

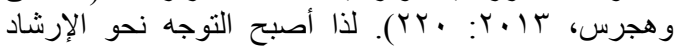

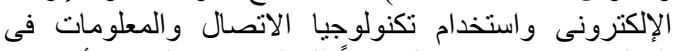

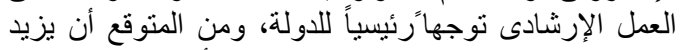

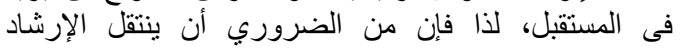

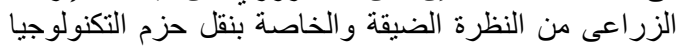

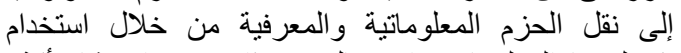

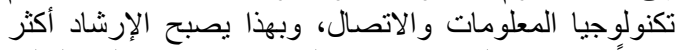

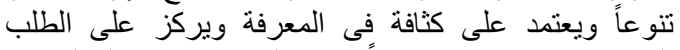

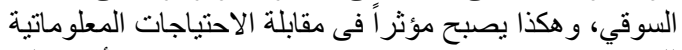

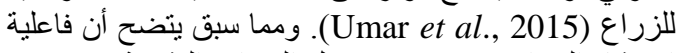

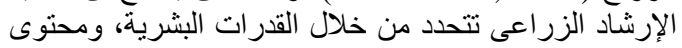

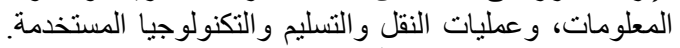

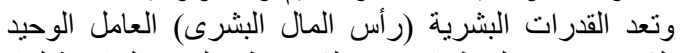

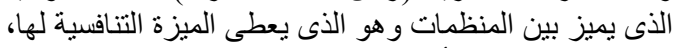

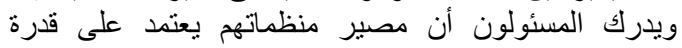

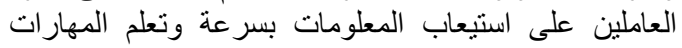

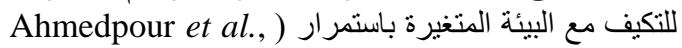

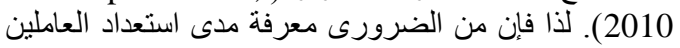

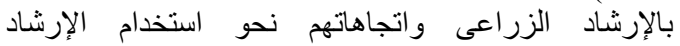

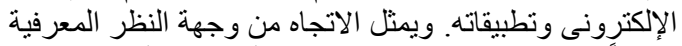

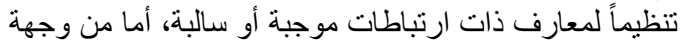

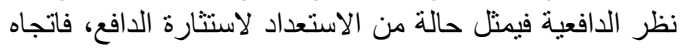

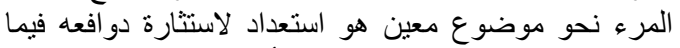

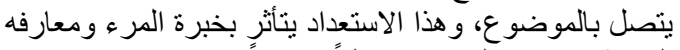

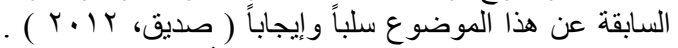

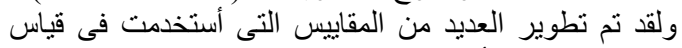

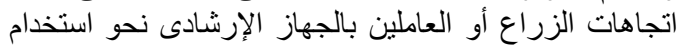

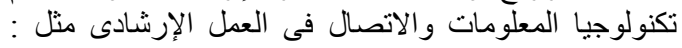
Kumar and Ratnakar ، Verma et al. (2014)

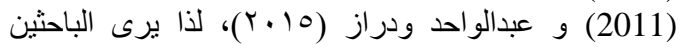

\section{مقدمة ومشكله الار اسة}

يهدف البحث العلمى فى قطاع الزراعة إلى زيادة الإنتاجية

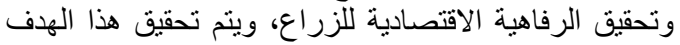

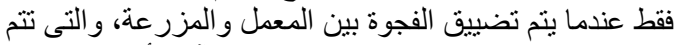

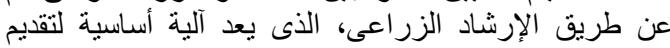

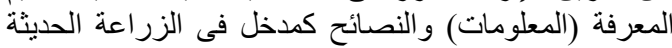

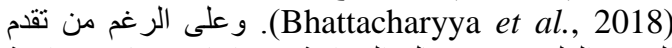

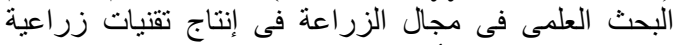

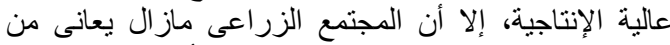

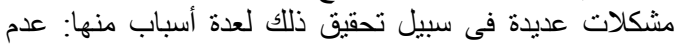

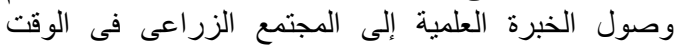

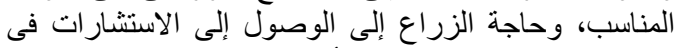

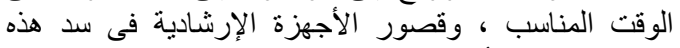

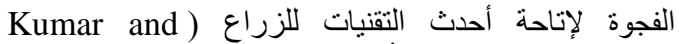

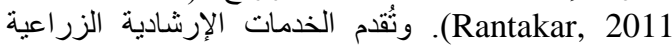

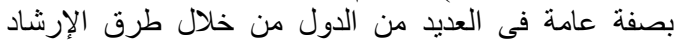

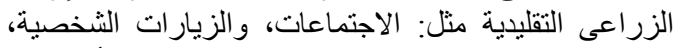

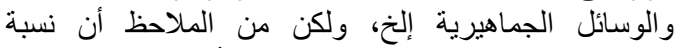

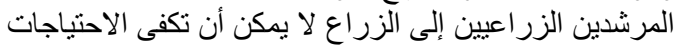

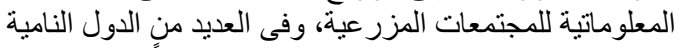

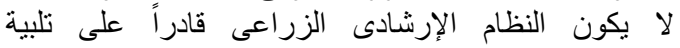

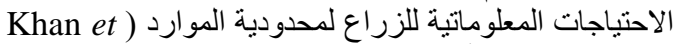

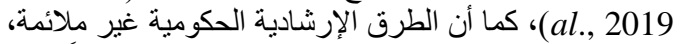

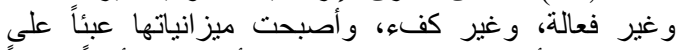
الحكومة، وأصبحت عملية إصلاحها أوتحديثها أمراً حتمياً

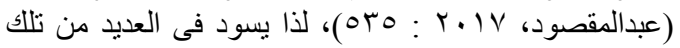

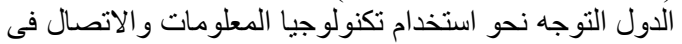

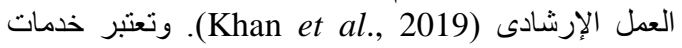

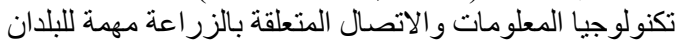

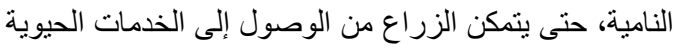

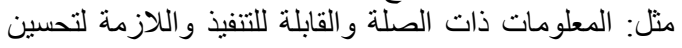

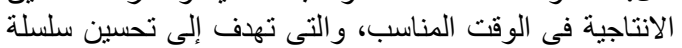

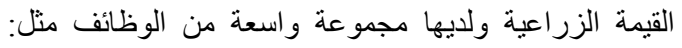

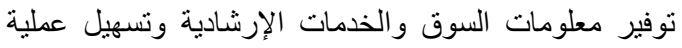

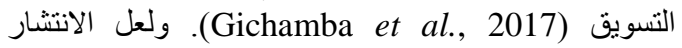
السريع لتكنولوجيا المعلومات و الاتصال فى الدول النامية وفر الأنيار

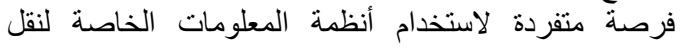

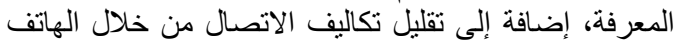

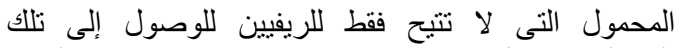

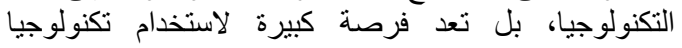

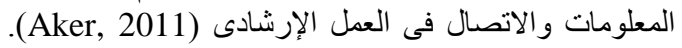

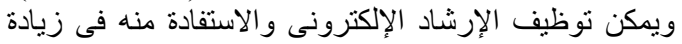

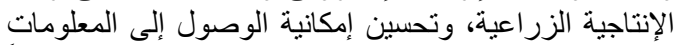

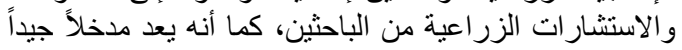

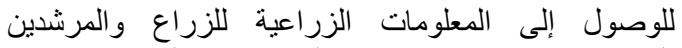

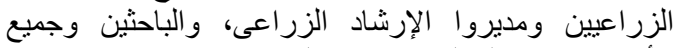
الأطراف ذات الصلة بالإرشاد الزراعى ( Sweta et al., الزراعي 
ا. السن : تم قياسه بعدد سنوات عمر المبحوثين لأقرب سنة

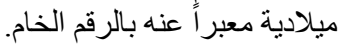

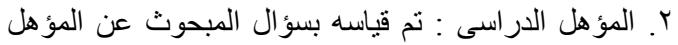

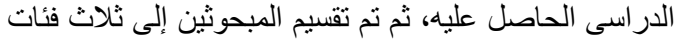

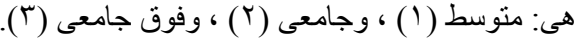

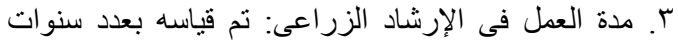

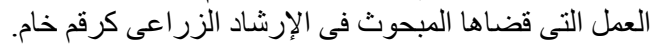
ء. التدريب على تكنولوجيا المعلومات والاتصال: تم قياسه

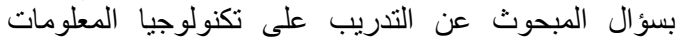
والاتصال الذى تلقاه، ثم تم تقسيم المبحوثين إلى فئتين هما:

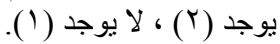

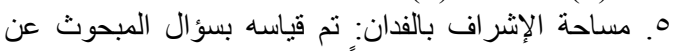
مساحة الإشر اف بالفدان معبراً عنه بالرقم الخام.

القسم الثانى: تحديد اتجاهات المبحوثين نحو الإرشاد الإلكترونى: - (الفين

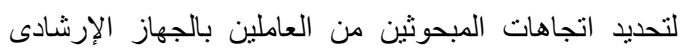

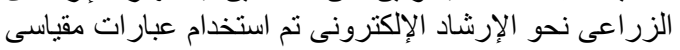

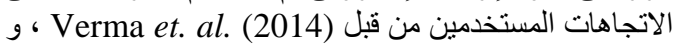
Kumar and Ratnakar (2011) اتجاهات الزراع والعاملين بالجهاز الإرشادى نحو استخدام

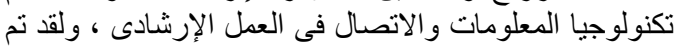

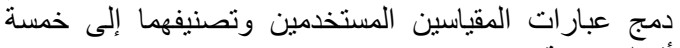
أقستام رئيسة هئ:

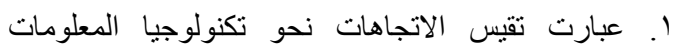

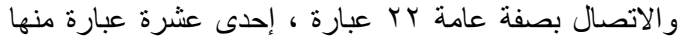
سلبية و إحدى عثرة عبارة إيجابية.

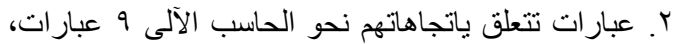
أربع عبار ات منها سلبية و الخمس عبار اتهات اتهات الأخرى إيجابية.

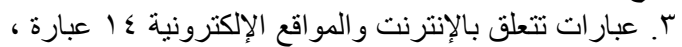

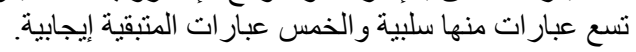

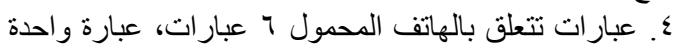
منها سلبية و الخمس عبار ات المتبقية إيجابية.

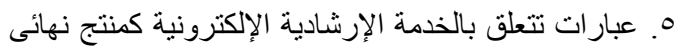

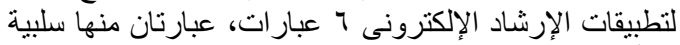
و الأربع المتبقية عبار ات إيجابية.

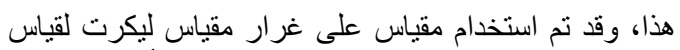

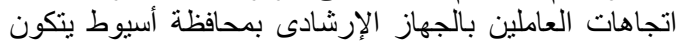

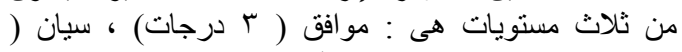

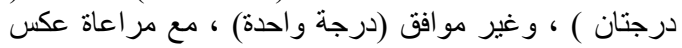

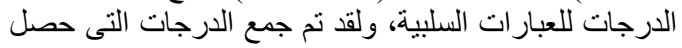

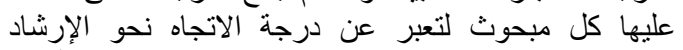

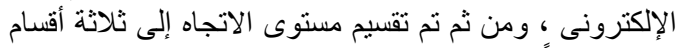

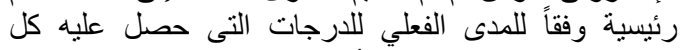

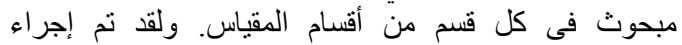
التعديلات اللازمة للمقياس حتى يتناسب مع المجتمع المصري المبري
أهمية التعرف على اتجاهات العاملين بالجهاز الإرشادى نحو

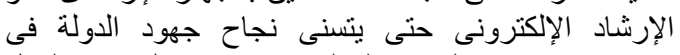

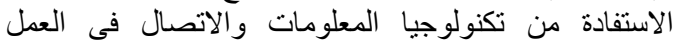

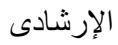

\section{أهداف البحث}

يستهدف هذا البحث بصفة رئيسية تحديد اتجاهات العاملين بالجهاز الإرشادى الزراعى نحو الإرشاد الإلكترونى بمحافظة أسيوط :

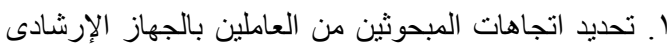

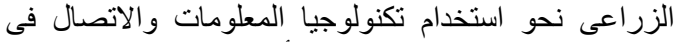

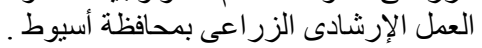

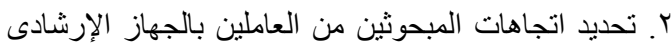

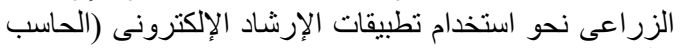

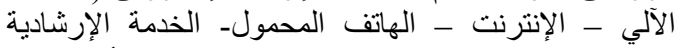
الإلكترونية) فى العمل الإرشادى الزر اعى بمحافظة أسيوط.

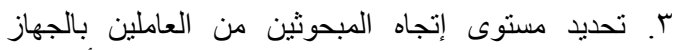
الإرشادى الزراعى نحو الإرشاد الإلكترونى بمحافظة أسيوط.

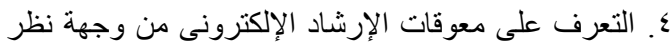

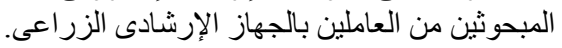

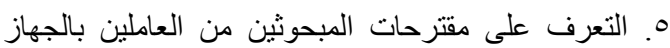

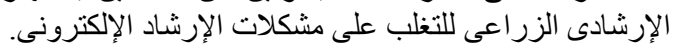

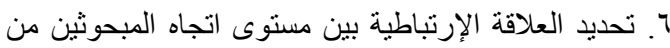

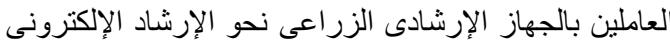

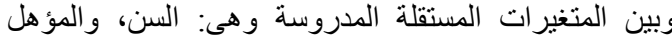

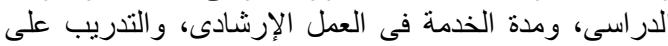

تكنولوجيا المعلومات و الاتصال، ومساحة الإشر اف الف بالفدان.

\section{الفروض البحثية}

لتحقيق الهدف السادس تم صياغة الفرض البحثى النالى: توجد البهن

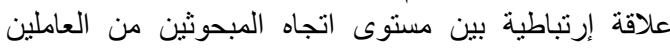

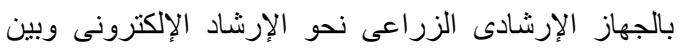

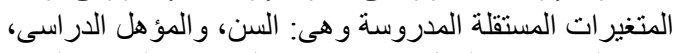

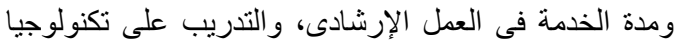

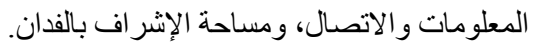

\section{الطريقة البحثية}

تم إجراء هذا البحث على عينة عشوائية من العاملين بالجهاز

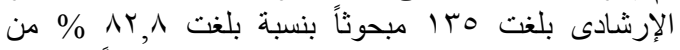

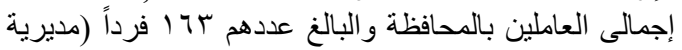

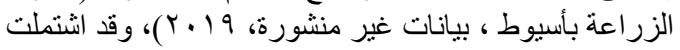
استمارة الاستبيان على ثلاثة أقسام تنتاول:

والقسم الأول: يتعلق ببعض المتغيرات الثخصية والمهنية 
العمل الإرشادى الزراعى، و اتجاه المبحوثين نحو تطبيقات

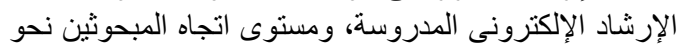

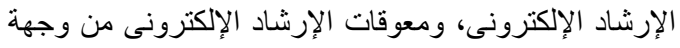

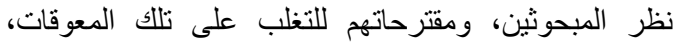

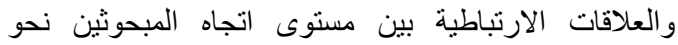
الإرشاد الإلكترونى وبين المتغير ات المستقلة المدروسة.

\section{أولا: وصف عينة البحث}

تشير النتائج الواردة بالجدول (1) إلى أن غالبية المبحوثين

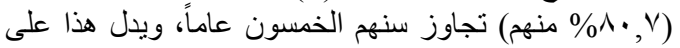

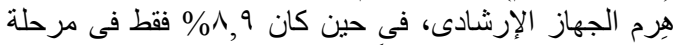
الثباب أقل من أربعين عاماً، وأن ما يقرب من من ثلثنى المبحوثين

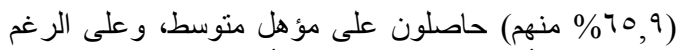

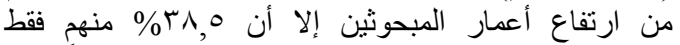

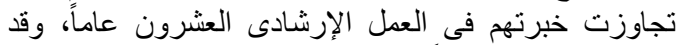

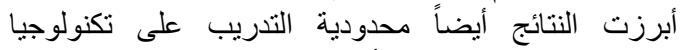

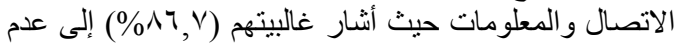

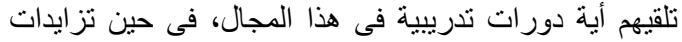

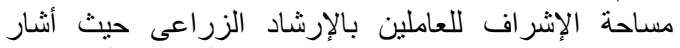

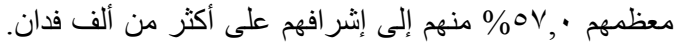

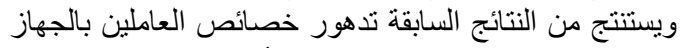
الإرشادى وخاصة فيما يتعلق بتقدم أعمار هم وزيادة مساحة لإنة

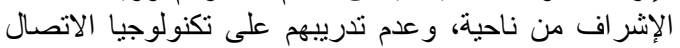
و المعلومات من ناحية أخرى. ناحية وعرم.
وفقاً لنتائج الاختبار المبدئي للاستمارة (pretest) الذي تم

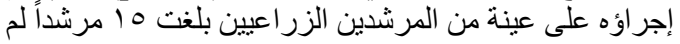

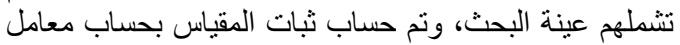

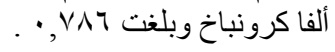

القسم الثالث: يتعلق بالمعوقات التى تحد من تطبيق الإرشاد

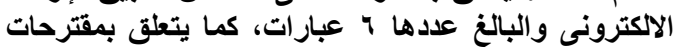
التغلب على تلك المعوقات بوضع عدول عدد ستة عبارات:

وتم جمع البيانات من خلال المقابلة الثخصية باستخدام

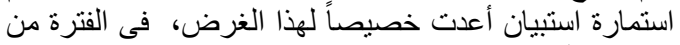

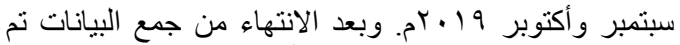

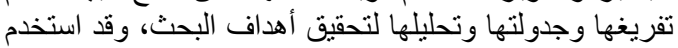

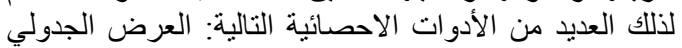

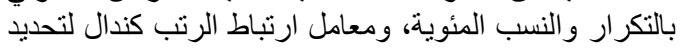

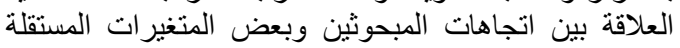

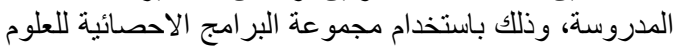

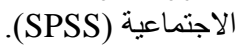

\section{النتائج ومناقشتثها}

اشتملت نتائج هذا البحث على وصف لعينة البحث، والنتائج

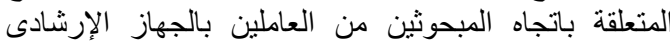

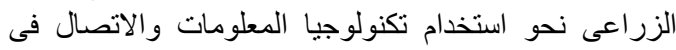

جدول ( (1): التوزيع العددى و النسبى للمبحوثين وفقاً لخصائصهم المدروسة ( ن= هب ().

\begin{tabular}{|c|c|c|}
\hline \multicolumn{3}{|r|}{ الخصــائــــــ } \\
\hline \multicolumn{3}{|r|}{ 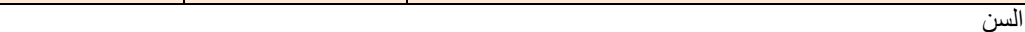 } \\
\hline$\wedge, 9$ & IT & • ـ سنة فأقل \\
\hline $1 \cdot, \varepsilon$ & $1 \varepsilon$ & | \\
\hline$\Lambda \cdot, \mathrm{V}$ & 1.9 & أكبر من •0 سنة \\
\hline & & المؤهل الدراسى \\
\hline 70,9 & 19 & 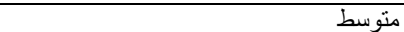 \\
\hline Tr, & «o & جامعى ( جامى \\
\hline$\cdot, \mathrm{V}$ & 1 & فوق جامعى \\
\hline \multicolumn{3}{|r|}{ مدة الخدمة فى العمل الإرشادى } \\
\hline$r \leqslant, 1$ & $\leqslant 7$ & • • إنوات فأقلَ \\
\hline TV, $\varepsilon$ & TV & 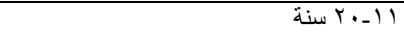 \\
\hline$r \Lambda, 0$ & or & أكثر من ·r سنة \\
\hline \multicolumn{3}{|r|}{ التدريب على تكنولوجيا الاتصال و المعلومات } \\
\hline $1 r, r$ & 11 & يوجد \\
\hline$\Lambda 7, \vee$ & $11 \mathrm{~V}$ & لا يوجد \\
\hline \multicolumn{3}{|r|}{ مساحة الإشر اف بالفدان } \\
\hline$\varepsilon r$, & 01 & أقل من ... \\
\hline $17, r$ & TY & 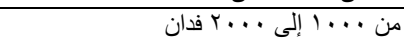 \\
\hline$\varepsilon \cdot V$ & 00 & أكثر من · ... ب فدان \\
\hline
\end{tabular}


الزبحوثين نحو استخدام الحاسب الآلى فى العمل الإرشادى

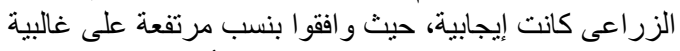

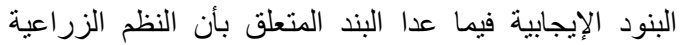

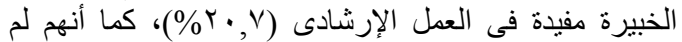

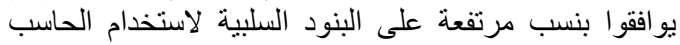

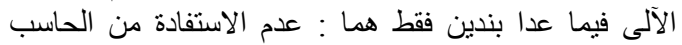

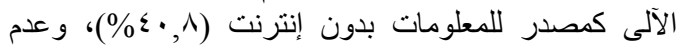

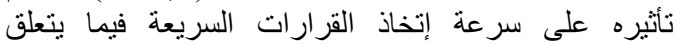

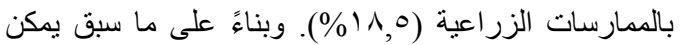

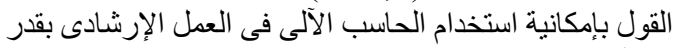

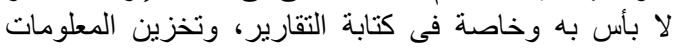

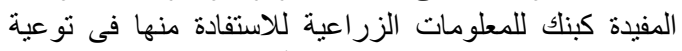

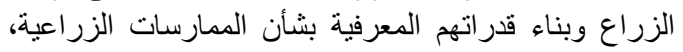

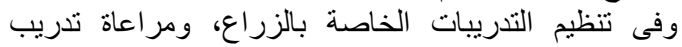

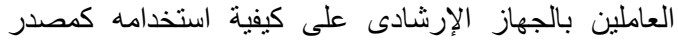
للمعلومات، والاستفادة من المعلومات الزئل الزراعية فى النظم

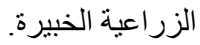

r. الإنجاهات المبحوثين نحو استخدام الإنترنت فى العمل الإرشادى الزراعى الجيج

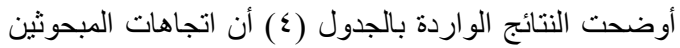

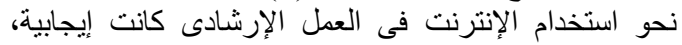

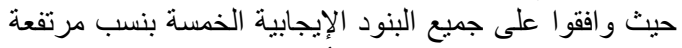

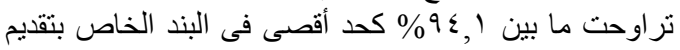

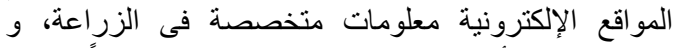

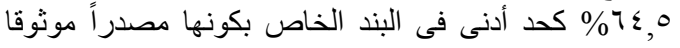

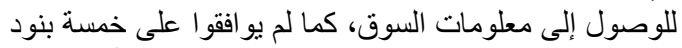

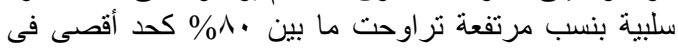

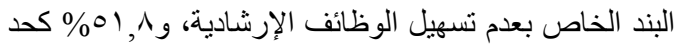

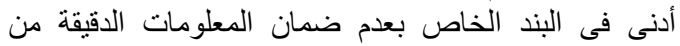

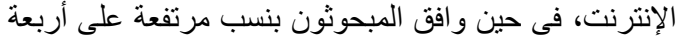

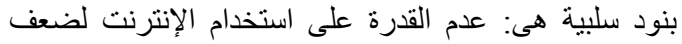

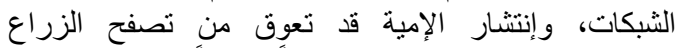

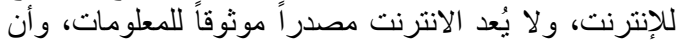

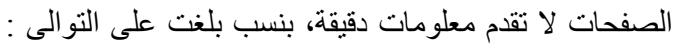

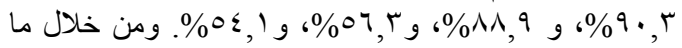

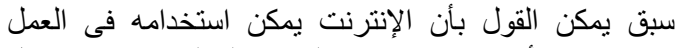

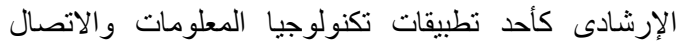

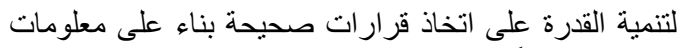

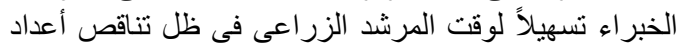

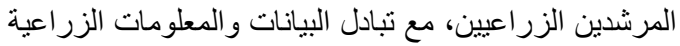

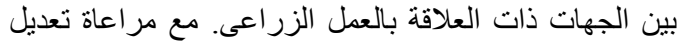

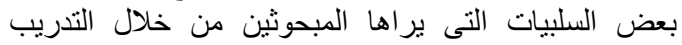
و التثقيف حول كيفية الوصول إلى المعلومات الدقيقة والموثنوق

فيها.
ثانيا: اتجاهات المبحوثين نحو استخدام تكنولوجيا

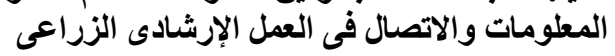

أشارت النتائج الواردة بالجدول (r) إلى أن غالبية المبحوثين

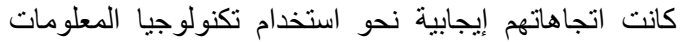

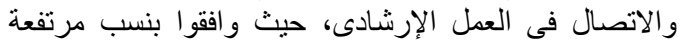

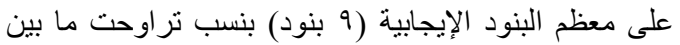

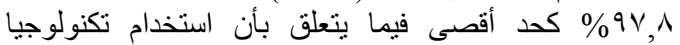

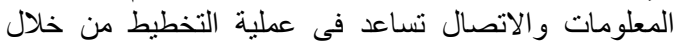

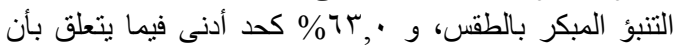

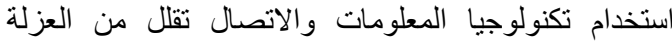

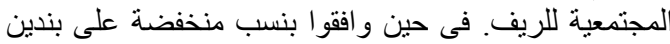

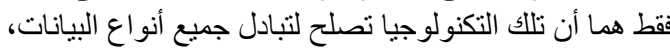

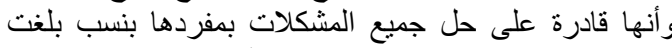

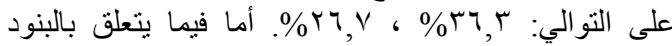

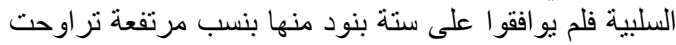

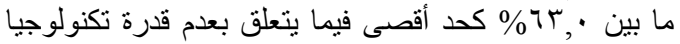

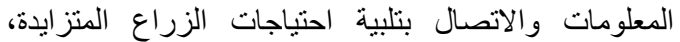

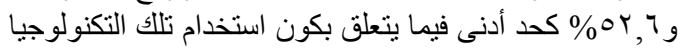

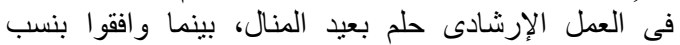

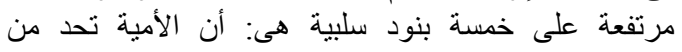

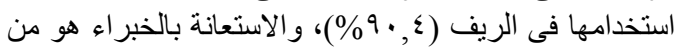

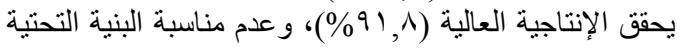

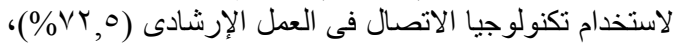

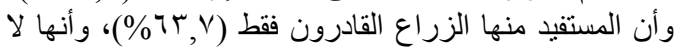

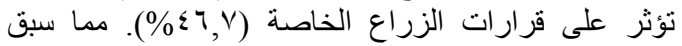

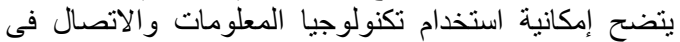

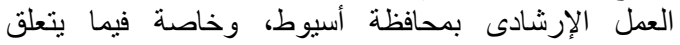

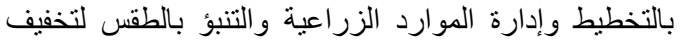

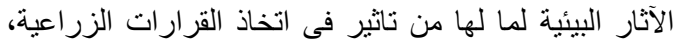

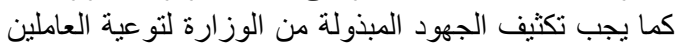

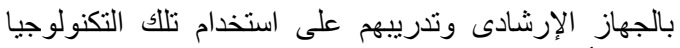

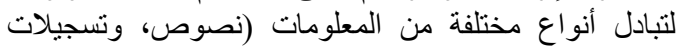

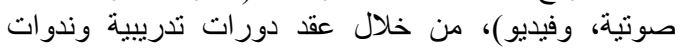

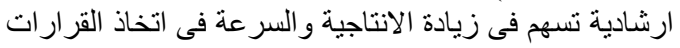

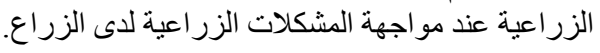

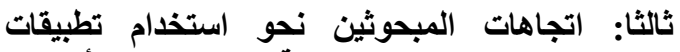

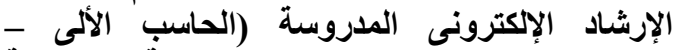

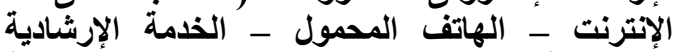
الإكترونية) فى العمل الإرشادى الزراعى بمحافظة أسيوط

ا ـ اتجاهات المبحوثين نحو استخدام الحاسب الآلى فى العمل الإرشادى الزراعى المبحون

أنشارت النتائج الواردة بالجدول (r) إلى أن اتجاهات 
Abdelsalam and Mahmoud / Archives of Agricultural Sciences Journal 2(3) 15-26, 2019.

\begin{tabular}{|c|c|c|c|c|c|c|c|}
\hline \multirow{3}{*}{ الاتجاه } & \multicolumn{6}{|c|}{ الاتجاهات } & \multirow{3}{*}{ 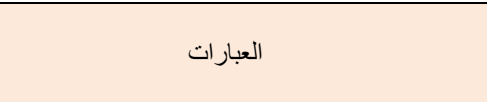 } \\
\hline & \multicolumn{2}{|c|}{ غير مو افق } & \multicolumn{2}{|c|}{ محايد } & \multicolumn{2}{|c|}{ 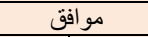 } & \\
\hline & $\%$ & عدد & $\%$ & عدد & $\%$ & عدد & \\
\hline+ & 1,0 & r & $\cdot, \mathrm{V}$ & 1 & $9 V, \Lambda$ & ITr & تساعدنى فى عملية التخطيط خلال التنبؤ المبكر بالطقس \\
\hline+ & $7 \cdot, \cdot$ & Al & 1,0 & r & $r \Lambda, 0$ & or & لا تساعد سد الفجوة بين نسبة الزر اع إلى المرشدين \\
\hline+ & $r, \Lambda$ & $\varepsilon r$ & $0, r$ & $\mathrm{~V}$ & $7 \pi$, & 10 & تقلل من عزلة المجتمع الزراعى \\
\hline+ & $7 \%$. & 10 & $r, y$ & 0 & $r \mu, r$ & «0 & غير قادرة على تلبية احتياجات الزر اع المتز ايدة \\
\hline+ & $r$, & $\varepsilon$ & $\cdot, \mathrm{V}$ & 1 & $97, r$ & $1 \pi \cdot$ & تسهل إدارة الموارد وتخفيف المخاطر البيئية \\
\hline+ & $09, r$ & $\wedge$. & $0, r$ & $\mathrm{v}$ & $r 0,7$ & $\sum \wedge$ & لا يعتمد عليها كسياسة زر اعية فعالة \\
\hline+ & $r r, Y$ & rt & $r, r$ & $r$ & $V \leqslant, \cdot$ & $1 \cdots$ & تقدم الحلول الممكنة للزر اع فى الوقت المناسب \\
\hline+ & $07, r$ & $V 7$ & 0,9 & $\Lambda$ & $r v, \Lambda$ & 01 & لا تمكننى من مقابلة الاحتياجات المحلية للزر اع \\
\hline+ & 11,1 & 10 & $\varepsilon, \varepsilon$ & 7 & $\Lambda \varepsilon, \leqslant$ & $11 \leq$ & تمكننى من الوصول إلى المزارع ذو الحاجة \\
\hline+ & 11,1 & 17 & 0,9 & $\Lambda$ & NY,, & 111 & الاستجابة أسرع من الطرق التقليدية \\
\hline- & $\mathrm{V}, \varepsilon$ & 1. & $r, r$ & $r$ & $9 \cdot, \varepsilon$ & TYY & تحد الأمية من استخدامها بين الزراع \\
\hline+ & $7 \cdot, \mathrm{V}$ & Ar & $0, r$ & $\mathrm{~V}$ & $r \leqslant, 1$ & $\sum 7$ & لا تصلح للاتصال الثخصى \\
\hline+ & or, 7 & VI & 11,1 & 10 & $r 7, r$ & $\varepsilon 9$ & حلم بعيد المنال عن الزراع \\
\hline+ & $1 \leqslant, \wedge$ & r. & $\wedge, 1$ & 11 & $V V_{,}$ & $1 \cdot \varepsilon$ & تساعد المزارع على التسويق بأسعار مجزية \\
\hline- & r,a & $\varepsilon$ & $0, r$ & $\mathrm{v}$ & 91,1 & $1 Y \varepsilon$ & الاستعانة بالخبر اء فقط تزيد الانتاجية \\
\hline- & $0 \leqslant, 1$ & $\mathrm{NT}$ & 9,7 & $1 \pi$ & $r$ & $\leqslant 9$ & تصلح لتبادل المعلومات بجميع أنو اعها \\
\hline- & YI,0 & r9 & 0,9 & $\Lambda$ & $V Y, 0$ & 91 & البنية الأساسية غير كافية لاستخدامها بالريف \\
\hline- & $r 7$, & ro & $1 \cdot, \varepsilon$ & $1 \leqslant$ & $7 r, \mathrm{~V}$ & $\Lambda \mathrm{T}$ & يستفيد منها الزر اع القادرون فقط \\
\hline- & $T V, \varepsilon$ & 91 & 0,9 & $\Lambda$ & Y7,,$Y$ & ry & بمفردها قادرة على حل مشكلات الزراع \\
\hline+ & 0,9 & $\Lambda$ & $r, y$ & 0 & $9 \cdot, r$ & IYK & يسهل نظام الإنذار المبكر لاتخاذ التدابير اللازمة \\
\hline- & $r \Lambda, 0$ & Or & $1 \leqslant, \wedge$ & $r$. & $\varepsilon 7, V$ & $7 \pi$ & أداة قيمة ولكن لا تؤثر فى القرارات الخاصة بالزراع \\
\hline+ & r, 9 & $\varepsilon$ & $r, r$ & $r$ & $9 \leqslant, 1$ & IrA & تساعد المرشدين فى اتخاذ القرار ات الوقتية \\
\hline
\end{tabular}

\begin{tabular}{|c|c|c|c|c|c|c|c|}
\hline \multirow{3}{*}{ الاتجاه } & \multicolumn{6}{|c|}{ الاتجاهات } & \multirow{3}{*}{ 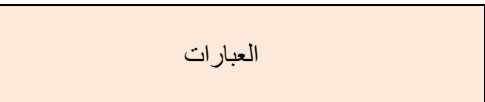 } \\
\hline & \multicolumn{2}{|c|}{ غير مو افق } & \multicolumn{2}{|c|}{ محايد } & \multicolumn{2}{|c|}{ 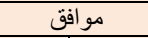 } & \\
\hline & $\%$ & عدد & $\%$ & عدد & $\%$ & عدد & \\
\hline+ & $0, Y$ & $\mathrm{~V}$ & 1,0 & $r$ & $94, \varepsilon$ & $1 \times 7$ & بساعد في سر عة الإبلاغ وكتابة التقارير \\
\hline+ & $70, Y$ & $\lambda \wedge$ & $0, Y$ & V & rq,7 & $\varepsilon$ & غير قادر على حل المشكلات المرتبطة بالزر اعة \\
\hline+ & $v, \varepsilon$ & 1. & 0,9 & $\wedge$ & $\Lambda V_{,} \cdot$ & $11 \mathrm{~V}$ & فعال في تتظيم التدريبات الخاصة بالزراع \\
\hline+ & $V 7, r$ & 1.4 & $r, Y$ & $r$ & YI, 0 & rq & لا بمكن استخدامه كبنك لتخزين المعلومات \\
\hline+ & $\mathrm{V}, \varepsilon$ & $1 \cdot$ & $r, \mathrm{r}$ & 0 & $\wedge \wedge, 9$ & Tr. & وسيلة قوية لبناء قدر ات المجنمع \\
\hline- & $\varepsilon \cdot, \wedge$ & 00 & $r, v$ & 0 & 00,7 & vo & مصدرا غير مفيد بدون إنترنت \\
\hline+ & $\wedge, 9$ & IT & $r, v$ & 0 & $\Lambda V, \varepsilon$ & 111 & به أدوات سهلة لنقل البيانات \\
\hline- & 11,0 & TO & $0, Y$ & $\mathrm{~V}$ & $v 7, r$ & $1 \cdot r$ & غير مفيد لاتخاذ قرار سريع بشأن الممارسات الزر اعية \\
\hline- & $V \leqslant, 1$ & $1 \cdots$ & $0, Y$ & V & $r \cdot, V$ & rA & النظم الزر اعية الخبيرة مفيدة \\
\hline
\end{tabular}

المصدر: استمارات الاستبيان. + اتجاه إيجابى. - إتجاه سلبى.

على العبارة السلبية الوحيدة وهى : أن الهاتف المحمول لا لإنا

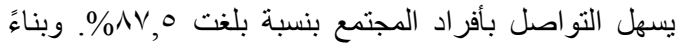

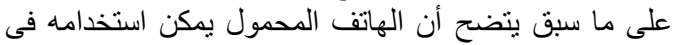

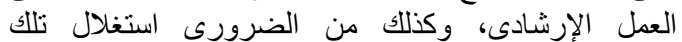

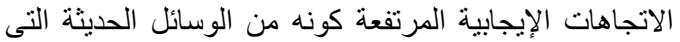

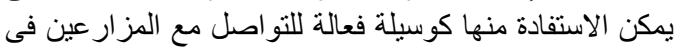

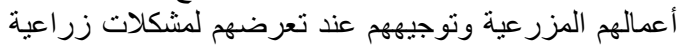

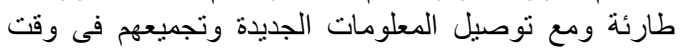

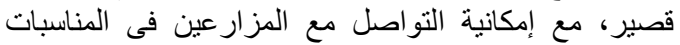

\section{r. اتجاهات المبحوثين نحو استخدام الهاتف المحمول فى الري}

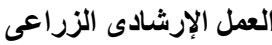

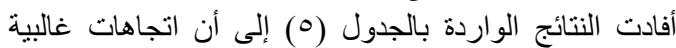

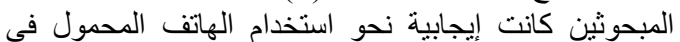

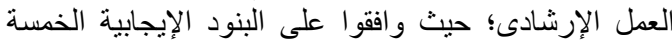

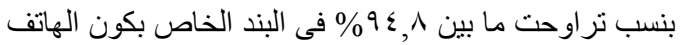

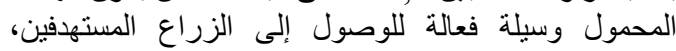

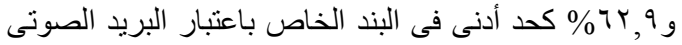

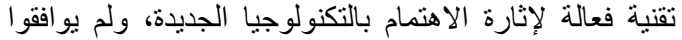


السعيدة أو الحزينة من قبل العاملين بالجهاز الإرشادى، ومن الإكترونى إذا ما تم تطبيقه فى العمل الإرشادى الزراعى الإسى

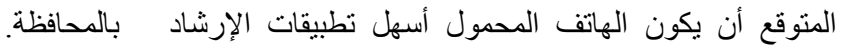

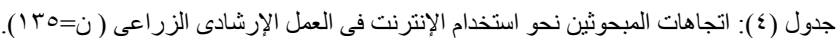

\begin{tabular}{|c|c|c|c|c|c|c|c|}
\hline \multirow{3}{*}{ الاتجاه } & \multicolumn{6}{|c|}{ 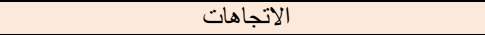 } & \multirow{3}{*}{ 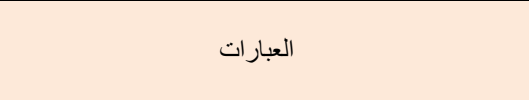 } \\
\hline & \multicolumn{2}{|c|}{ غير مو افق } & \multicolumn{2}{|c|}{ محايد } & \multicolumn{2}{|c|}{ مو افق } & \\
\hline & $\%$ & عدد & $\%$ & عدد & $\%$ & عدد & \\
\hline- & $\Lambda, 9$ & Tr & r, r & r & $\wedge \wedge, 9$ & Tr. & الأمية تعوق الزراع لتصفح الانترنت \\
\hline+ & 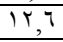 & IV & 1,0 & r & $\wedge \tau$, & 117 & يحسن الإنترنت قدرة الإرشّاد فى اتخاذ القرار \\
\hline+ & 01,1 & $V \cdot$ & $0, r$ & V & $\varepsilon r$, & $0 \wedge$ & لا يمكن ضمان المعلومات الدقيقة \\
\hline+ & 11,1 & 10 & 1,0 & r & $\Lambda V, \Sigma$ & 111 & الربط بين الإدار ات الزر اعية و الإدار ات المتعاونة معها \\
\hline+ & $V \varepsilon, \wedge$ & 1.1 & $0, r$ & $\mathrm{~V}$ & $r \cdot, \cdot$ & TV & لا يساعد فى إدارة المخاطر الزراعية \\
\hline+ & $77, \cdot$ & 19 & $r, r$ & 0 & $r \cdot, r$ & $\leqslant 1$ & تمضية الوقت بين الزراع و المرشدين \\
\hline- & $\varepsilon r$, & $0 \wedge$ & $r$, & $\varepsilon$ & $0 \leqslant, 1$ & $\frac{V T}{V T}$ & الصفحات ليست مصدر أ دقيقاً للمعلومات \\
\hline+ & ro, 9 & ro & 9,7 & 14 & $7 \leqslant, 0$ & $\Lambda V$ & المو اقع الإلكترونية موثوق فيها للوصول إلى معلومات السوق \\
\hline - & $\wedge, 9$ & ir & $\cdot, \mathrm{Y}$ & 1 & $9 \cdot, r$ & Irt & ضrف الإنترنت في المناطق الريفية بعيق تطبيقه \\
\hline+ & $\Lambda \cdot, \cdot$ & $1 \cdot 1$ & $r, r$ & $r$ & $I V, \wedge$ & $r \varepsilon$ & لا يستطيع تسهيل الوظائف الإرشادية \\
\hline+ & $\varepsilon, \varepsilon$ & 7 & 1,0 & r & $9 \leqslant, 1$ & ITV & تقدم المو اقع الالكترونية المعلومات المتخصصة فى الزر اعة \\
\hline+ & 9,7 & $1 \pi$ & $\varepsilon, \xi$ & 7 & 10,9 & 117 & توفر الثبكات المعلومات بلغة مفهومة \\
\hline+ & $7 \varepsilon, \varepsilon$ & 19 & $0, r$ & $\mathrm{~V}$ & $r \cdot, \varepsilon$ & $\sum 1$ & تحتاج لوقت كبير للحصول على المشورة من خلال الأنترنت \\
\hline- & $r 7, r$ & $\sum 9$ & $\mathrm{v}, \varepsilon$ & $1 \cdot$ & $07, r$ & $V 7$ & لا تعتبر مصدر أ موثوقا فيه \\
\hline
\end{tabular}

المصدر: استمار ات الاستبيان. + اتجاه إيجابى. - إتجاه سلبى.

\begin{tabular}{|c|c|c|c|c|c|c|c|}
\hline \multirow{3}{*}{ الاتجاه } & \multicolumn{6}{|c|}{ الاتجاهات } & \multirow{3}{*}{ 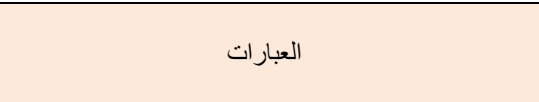 } \\
\hline & \multicolumn{2}{|c|}{ غير مو افق } & \multicolumn{2}{|c|}{ محايد } & \multicolumn{2}{|c|}{ مو افق } & \\
\hline & $\%$ & عدد & $\%$ & عدد & $\%$ & عدد & \\
\hline+ & $1 \leqslant, 1$ & 19 & r, & $r$ & Nr,, & 114 & يقلل من العزلة الاجتماعية للريفيين \\
\hline+ & $0, Y$ & V & - & - & $9 \leq, \wedge$ & 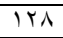 & وسيلة فعالة للوصول إلى الزراع المستهدفين \\
\hline+ & $\Lambda V_{, 0}$ & 111 & 1,0 & r & 11,1 & 10 & لا يسهل التو اصل بين أفراد المجتمع الزراعى \\
\hline+ & $r \cdot, Y$ & rA & $17, r$ & Tr & 74,9 & 10 & البريد الصوتى تقنية فعالة لإثارة الآهتمام بالتكنولوجيا الجديدة \\
\hline+ & YY,Y & $r$ & 0,9 & $\Lambda$ & $\vee, \wedge$ & 91 & وسيلة ليست مكلفة لتبادل المعلومات \\
\hline+ & 9,7 & ir & 1,0 & $r$ & $\wedge \wedge, 9$ & Ir. & الاتصال التليفونى المباشر يعطى معلومة مفيدة \\
\hline
\end{tabular}

المصدر: استمار ات الاستبيان. + اتجاه إيجابى. - إتجاه سلبى.

للجهد، إلا أنه ينطلب مزيداً من حضور للاورات التندريبية

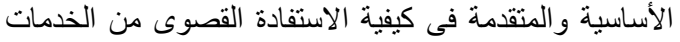
الالكترونية فى العمل الإرشادى.

\section{رابعا: مستوى اتجاهات المبحوثين نحو الإشثاد الزراعى الإلكترونى بمحافظة أسيوط}

أشارت النتائج الواردة بالجدول (V) إلى أن الن مستوى اتجاه

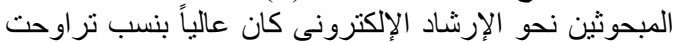

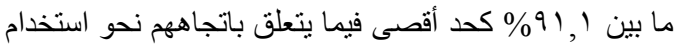

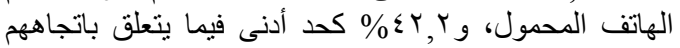

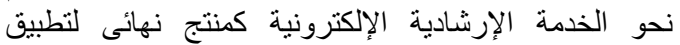

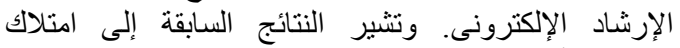
و استخدام أغلب المبحوثين للهاتف المحمول قد يكون بقدر كبير

\section{4. اتجاهات المبحوثين نحو الخدمة الإرشادية الإكترونية}

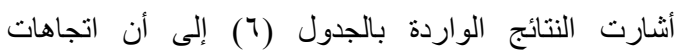

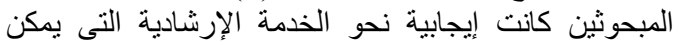

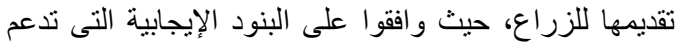

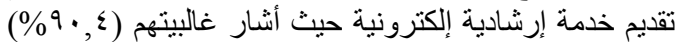

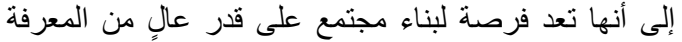

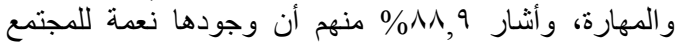

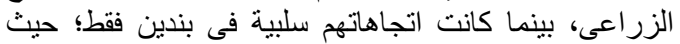

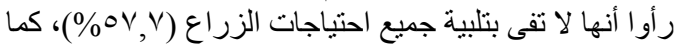

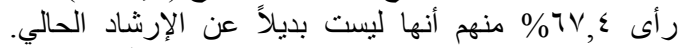

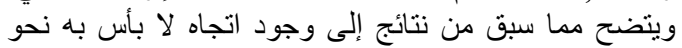

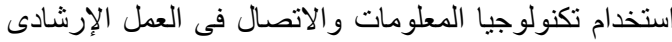

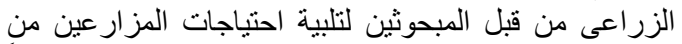

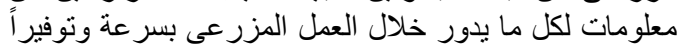


المسترشدين، ورذا يتطلب ضرورة الاهتمام بزيادة التوعية

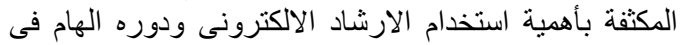

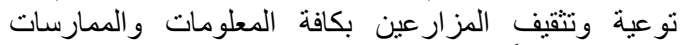

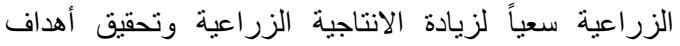

التنمية الزر اعية المستدامة.

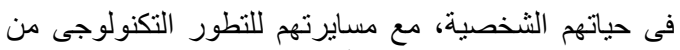

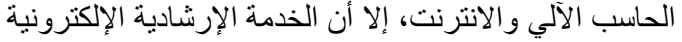

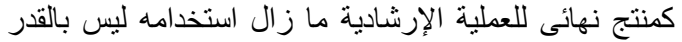

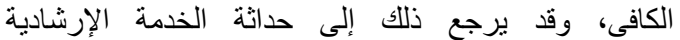

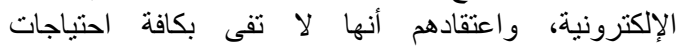

جدول (†): اتجاهات المبجوثين نحو الخدمة الإرشادية الإكترونية ( ن=ه ب ().

\begin{tabular}{|c|c|c|c|c|c|c|c|}
\hline \multirow{3}{*}{ الاتجاه } & \multicolumn{6}{|c|}{ الاتجاهات } & \multirow{3}{*}{ 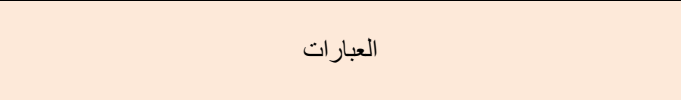 } \\
\hline & \multicolumn{2}{|c|}{ غبر مو افق } & \multicolumn{2}{|c|}{ محايد } & \multicolumn{2}{|c|}{ مو افق } & \\
\hline & $\%$ & عدد ع ع ع & $\%$ & عدد ع ع ع & $\%$ & عدد & \\
\hline- & $r \bar{r}, r$ & $\leqslant 9$ & 0,9 & $\Lambda$ & ov,, & $V \lambda$ & الخدمة الإرشادية الإلكترونية ليست فعالة فى تلبية الاحتياجات الزراع \\
\hline+ & $07, r$ & V7 & $r, r$ & $r$ & $\Sigma 1,0$ & 07 & معر فة المرشدين الزر اعيين ضعيفة بكيفية تقديم الخدمة الإرشادية الإلكترونية \\
\hline+ & 0,9 & $\Lambda$ & $0, r$ & V & $\wedge \wedge, q$ & Tr. & وجود الخدمة الإرشادية الإلكترونية نعمة للمجتمع الزراعى \\
\hline+ & 01,9 & $\checkmark \cdot$ & 0,9 & $\Lambda$ & $\varepsilon r, r$ & ov & الخدمات الإرشادية الإلكترونية تتجنب الاتصال الفردي \\
\hline+ & $V, \varepsilon$ & $1 \cdot$ & $r, Y$ & $r$ & $9 \cdot, \varepsilon$ & TYY & الخدمات الإرشادية الإلكترونية تقدم فرصاً جديدة لبناء مجتمع المعرفة و المهارة \\
\hline- & $T V, \varepsilon$ & 91 & $\mathrm{v}, \varepsilon$ & 1. & ro,, & $r \varepsilon$ & الخدمات الإرشادية الإلكترونية بديلاً عن النظام الإرشادى الحالي \\
\hline
\end{tabular}

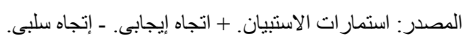

جدول (V): مستوى اتجاه المبحوثين نحو الإرشاد الإلكترونى بمحافظة أسيوط (ن=ه广 ا).

\begin{tabular}{|c|c|c|c|c|c|c|}
\hline \multicolumn{6}{|c|}{ مستوى الاتجاه } & \multirow{3}{*}{ التطبيقات } \\
\hline \multicolumn{2}{|c|}{ عال } & \multicolumn{2}{|c|}{ متو سط } & \multicolumn{2}{|c|}{ منخفض } & \\
\hline$\%$ & عدد & $\%$ & عدد & $\%$ & عدد & \\
\hline$v 1,1$ & 97 & $r T, y$ & rr & $0, Y$ & V & تكنولوجيا الاتصال و المعلومات \\
\hline$V \leqslant, \wedge$ & 1.1 & $19, r$ & $r 7$ & 0,9 & $\Lambda$ & الحاسب الآلي \\
\hline$V \cdot, \varepsilon$ & 90 & $r 7, V$ & ry & $r$, & $\varepsilon$ & الانترنت \\
\hline 91,1 & TKT & $7, V$ & 9 & T,Y & $r$ & الهاتف المحمول \\
\hline$\varepsilon r, r$ & ov & or, r & VY & $\varepsilon, \varepsilon$ & 7 & الخدمة الإرشادية الإلكترونية \\
\hline
\end{tabular}

المصدر: استمار ات الاستبيان.

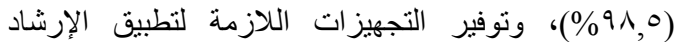
الإلكترونى مثل أجهزة الحاسب الآلى وشبكات الإنترنت الإنت

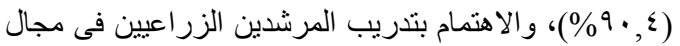

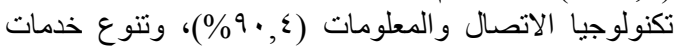

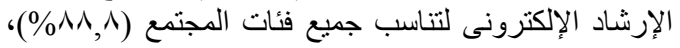

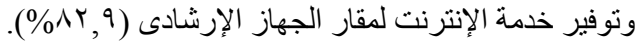

سابعا: العلاقات الارتباطية بين مستوى اتجاه المبحوثين الإنين

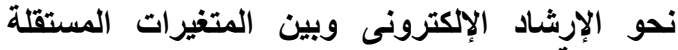
المدروسية

لاختيار صحة الفرض البحثي تم صياغة الفرض الاحتبائى التئي

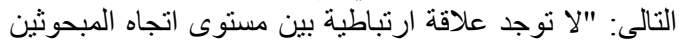

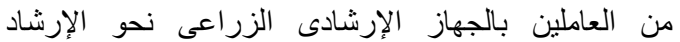

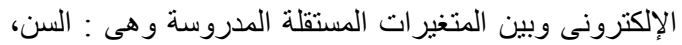

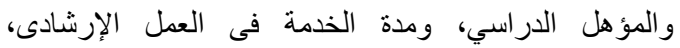

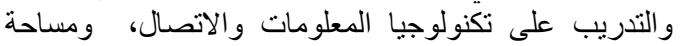

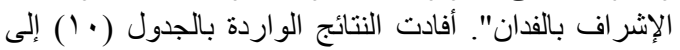
وجود علاقة ارتباطية طردية معنوية بين مستوى الجاه الجاه
خامسا: معوقات تطبيق الإرشاد الإكترونى من وجهة نظر المبحوثين

أوضحت النتائج الواردة في الجدول (^) إلى أن أهم المشكلات

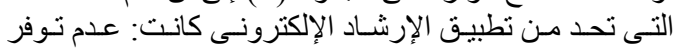

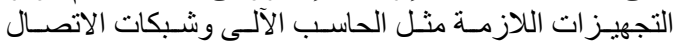

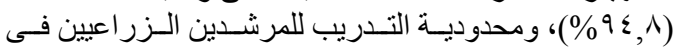

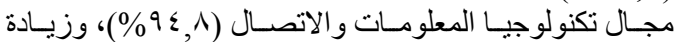

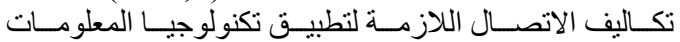

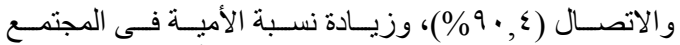

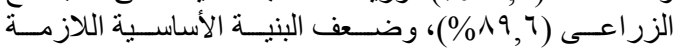

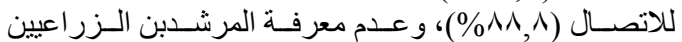

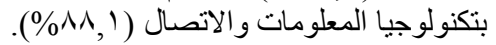

سادسا: مقترحات المبحوثين للتظلب على المعوقات التى الإنى

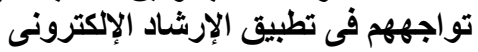

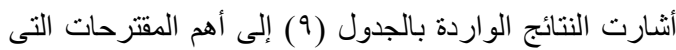

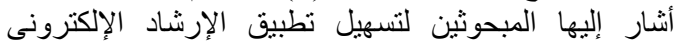
وكانت: زيادة الحوافز اللازمة لتطبيق الإرشاد الإلكترونى نطيق الإنئ 
المبحوثين نحو الإرشاد الإلكترونى وبين كل من المؤهل ونسينتج من هذه النتائج أهمية التعليم والتدريب كعاملين

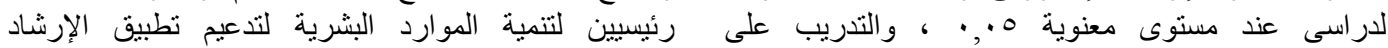

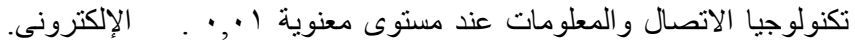

جدول (^): المعوقات التى تحد من تطبيق الإرشاد الإلكترونى من وجهة نظر المبحوثين ( ن= مب ا ).

\begin{tabular}{|c|c|c|}
\hline 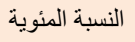 & عدد & المعوقات \\
\hline $9 \varepsilon, 1$ & TrA & عدم توفر التجهيزات اللازمة بمقار العمل الإرشادى \\
\hline $9 \varepsilon, 1$ & TrA & محدودية التدريب المتعلق بتكنولوجيا المعلومات و الاتصـال \\
\hline $9 \cdot, \varepsilon$ & ITY & زيادة تكاليف الاتصال اللازمة لنطبيق تكنولوجيا المعلومات و الاتصال \\
\hline 19,7 & $|r|$ & زيادة نسبة الأمية فى المجتمع الزر اعى \\
\hline$\Lambda \wedge, \wedge$ & Tr. & ضعف البنية الأساسية اللازمة للاتصال \\
\hline$\wedge \wedge, 1$ & 119 & عدم معرفة المرشدين الزر اعيين بتكنولوجيا الاتصـال و المعلومات \\
\hline
\end{tabular}

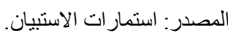

جدول (9): مقترحات المبحوثين للتغلب على المعوقات التى تحول دون تطبيق الإرشاد الإلكترونى ( ن= هب ا ).

\begin{tabular}{|c|c|c|}
\hline النسبة المئوية & عدد & المقترحات \\
\hline 91,9 & Tra & زيادة الحو افز اللازمة لتطبيق الإرشاد الالكتروني \\
\hline $9 \cdot, \varepsilon$ & TKY & تو فير التجهيز ات اللاز مة لتطبيق الإرشاد الالكتروني مثل الحاسب الآلى و الانترنت \\
\hline $9 \cdot, \varepsilon$ & IYY & الاهتمام بتدريب المرشدين في مجال تكنولوجيا الاتصال و المعلومات \\
\hline$\wedge \wedge, \wedge$ & Tr. & تتوع خذمات الإرشاد الالكتروني لتناسب جميع فئات المجتمع \\
\hline$\lambda r, 9$ & $11 \mathrm{~T}$ & توفير خدمة الإنترنت لمقار الجهاز الإرشادي \\
\hline
\end{tabular}

المصدر: استمار ات الاستبيان.

جدول (• ( ): معامل ارتباط الرتب لكندال بين مستوى اتجاه المبحوثين نحو الإرشاد الإلكترونى وبين المتغير ات المستقلة المدروسة.

\begin{tabular}{|c|c|c|}
\hline مستوى المعنوية & معامل الارتباط & المتغير ات المستقلة \\
\hline$\cdot, \leqslant \leqslant V$ & $\cdot, \cdot 77_{-}$ & 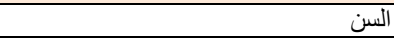 \\
\hline$\cdot, \mathrm{rA}$ & $\cdot, 101$ & المؤهل الدراسي \\
\hline 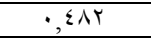 & $\cdot, \cdot \leqslant 0$ & مدة الخدمة فى العمل الإرشادى \\
\hline$\cdot, \cdot 1$ & ${ }^{* *} \cdot, \leqslant T r$ & التدريب على تكنولوجيا الاتصال و المعلومات \\
\hline$\cdot, \wedge \lambda)$ & $\cdot, \cdot 1 \cdot$ & مساحة الإشر اف بالفدان \\
\hline
\end{tabular}

نظر أ للاتجاهات الإيجابية المرتفعة نحو ذلك.

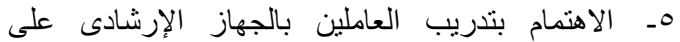

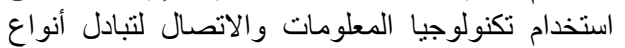

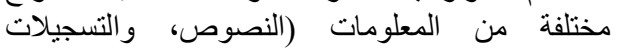

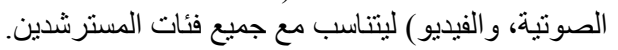

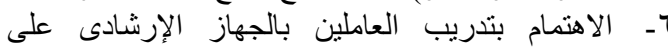
استخدام النظم الزراعبة الخبيرة.

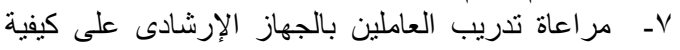

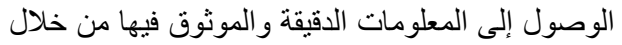
الإنترنت. استخدام تطبيقات الإرشاد الإلكترونى بجانب الإرشاد التقليدى

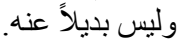

\section{قائمة المراجع}

الثافعي، عبد العليم أحمد، وهجرس، حسين على (r/ (Y).
من خلال النتائج التى تم التوصل إليها والاتجاهات الإيجابية

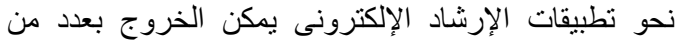
التوصيات الهامة على النحو التالى:

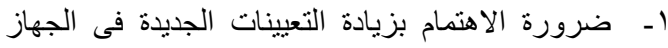

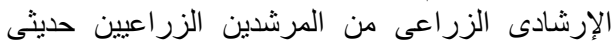

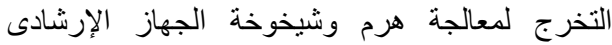

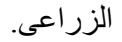
r- إمكانية استخدام تكنولوجيا الاتصال و المعلومات فى في ولئ العمل الإرشادى بمحافظة أسيوط وخاصة فئل في مجال

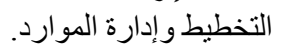

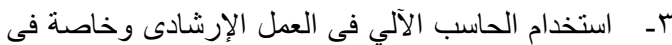
كتابة التقارير وكمخزن للمعلومات الإلي المفيدة، وفى تنظئي الدورات التدريبية للمسترشدين. ع- سهولة استخدام الهاتف المحمول فى العمل الإرشادى 


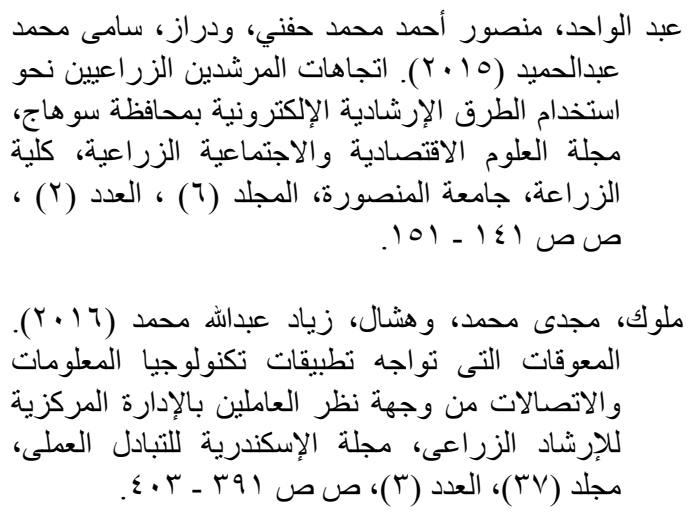

Ahmedpour, A., Mirdamadi, M., Hosseini, J. F, and Mohamad Chizari. (2010), "Factors affecting the development of electronic learning in agricultural extension network in Iran", Middle-East Journal of Scientific Research, Vol. 5 No. 4, pp. 261-267.

Aker, J. C. (2011), "Dial "A" for agriculture: a review of information and communication technologies for agricultural extension in developing countries", Agricultural Economics, Vol. 42, pp. 631-627.

Bhattacharyya, T., Patil, V. K., Bhave, S. G., Sawant, P. A., Haldankar, P. M. and Narkhede, S. S. (2018), "e-Extension services of SAUs in Indian agriculture: Challenges and management strategies", Advanced Agricultural Research \& Technology Journal, Vol. 2 No. 2, pp. 119-125.

Gichamba, A., Wagacha, P. W. and Danial O.O. (2017), "An assessment of eextension platforms in Kenya, International Journal of Innovative Studies in Sciences and Engineering Technology, Vo. 3 No. 7, pp. 36-40.

Khan, N.A, Qijie, G., Ali, S., Shahbaz, B. and Shah, A. A. (2019), "Farmers' use of

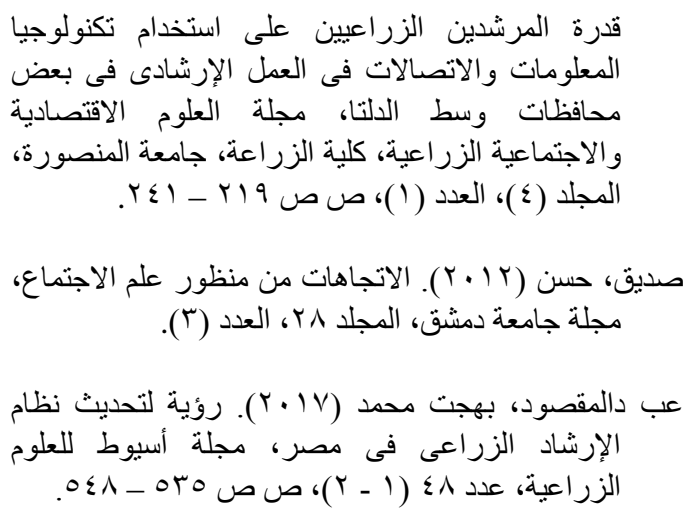

mobile phone for accessing agricultural information in Pakistan: a case of Punjab province", Ciência Rural, Santa Maria, Vol. 49, n. 10.

Kumar, P. G., and Ratnakar, R. (2011), "A Scale to Measure Farmers' Attitude towards ICT-based Extension Services", Indian Research Journal of Extension Education, Vol. 11, 109-112.

Kumar, R. N., Meena, S. R., Awasthi, O. P., Samadia, D. K., Singh, I. S., Jain, M. K. and Khatri, B. R. (2009), "Cyber extension in transfer of technology to farmers", International Journal of Tropical Agriculture, Vol. 27 No. 1-2, pp. 205-210:

Sweta, R., Pradhan, M K. and Singh, J. (2018), "Cyber extension for rural development", International Journal of Research in Agricultural Sciences, Vo. 5 No. 4, pp. 2348-3997.

Umar, S., Musa, M., Olayemi, Y. and Suliman, R. (2015), "Awareness and use of information and communication technologies among extension agents in Kaduna State of Nigeria", Journal of Agricultural Extension, Vol. 19 No. 1, pp. 
$66-76$.

Verma, S. R., Sharma, F. L., Panjapi, N. K. and R Bairwa, K. (2014), "Development of scale to measure attitude of extension personnel about information and communication technology application in agriculture", Indian Journal of Extension Education and Rural Development, Vol. 22, pp. 211-217. 